Revista de Estudos da Linguagem, Belo Horizonte, v. 23, n.2, p. 559-580, 2015

\title{
Mapeamentos metafóricos em artigo esportivo
}

\section{Metaphorical mappings in sports article}

\author{
Languisner Gomes \\ Universidade Estadual do Ceará (UECE), Fortaleza, Ceará, Brasil. \\ languisnergomes@hotmail.com
}

Resumo: O presente artigo discute o uso de algumas metáforas utilizadas para definir a atuação do jogador de futebol Hulk. Os dados foram retirados de um artigo esportivo selecionado do jornal O Povo, de Fortaleza - Ceará. A identificação das metáforas conceptuais, bem como dos respectivos mapeamentos que projetam as realizações metafóricas, visam determinar as possíveis gerações de sentido. Nosso objetivo principal na pesquisa é tentar responder ao seguinte questionamento: quais são os mecanismos de mapeamento envolvidos na geração do sentido metafórico? Para tanto, tivemos como objetivo subjacente descrever a estrutura da rede de mapeamentos conceptuais dos mecanismos responsáveis pela geração do sentido metafórico, motivo pelo qual escolhemos a Teoria da Metáfora Conceptual de Lakoff e Johnson (1980) e Lakoff(1987) para dar suporte às nossas análises.

Palavras-chave: mapeamentos metafóricos; metáforas conceptuais; geração sentido

Abstract: This article discusses some metaphors used to define the performance of the soccer player Hulk. The data were taken from an sport's article of the newspaper O Povo, in Fortaleza - Ceará. The 
identification of conceptual metaphors, as well as their respective mappings to design the metaphorical realizations, aimed at determining the possible production of meanings. Our main goal with this research is answering the following question: what are the mapping mechanisms involved in generating metaphorical sense? To this end, we had as underlying goal to describe the structure of the network of conceptual mappings of the mechanisms responsible for generating the metaphorical sense, which is why we chose the Theory of Conceptual Metaphor of Lakoff and Johnson (1980) and Lakoff (1987) to support our analysis. Keywords: metaphorical mappings; conceptual metaphor; meaning production

Recebido em 15 de setembro de 2014.

Aprovado em 20 de janeiro de 2015.

\section{Introdução}

A mente humana e as emoções são territórios de constante exploração. Muitas abordagens são alvos de investigação. A metáfora conceptual, apresentada por Lakoff e Johnson (1980), é um dos paradigmas que visa a apontar o que governa o pensamento humano. A rede de conceptualizações formadas na mente humana a capacita a dar sentido a diferentes expressões metafóricas.

Kövecses (2000) demonstrou que expressões verbais usadas para descrever emoções podem ser rastreadas por meio de um número limitado de metáforas conceptuais. A metáfora define-se como uma forma de processamento que, operando por mapeamento ou correspondência entre domínios da experiência, é capaz de licenciar em uma única e mesma expressão duas ou mais ideias ou representações diferentes. $\mathrm{O}$ objetivo de Kövecses (2000) é mostrar como as pessoas conceptualizam metaforicamente as emoções. $\mathrm{O}$ autor sugere que a conceptualização das emoções é, em certa extensão, universalmente compartilhada.

Compreendendo, pois, a relevância das conceptualizações realizadas pela mente humana, pretendemos, à luz dos princípios 
postulados por Lakoffe Johnson (1980) na Teoria da Metáfora Conceptual e Lakoff (1987), identificar as metáforas conceptuais, bem como os respectivos mapeamentos que projetam as realizações metafóricas, determinando as possíveis gerações de sentido, que constituem a base dos diferentes mapeamentos conducentes a diferentes realizações metafóricas.

Uma tendência na Linguística Cognitiva que inclui a metaforicidade como um dos casos especiais de mecanismos mais gerais dos mapeamentos mentais é a Teoria da Metáfora Conceptual, que procura explicar como os indivíduos constroem correspondências conceptuais e novas inferências. Entender como se processa a rede de mapeamentos é fundamental quando o que se pretende é demonstrar como se dá o processo de significação pela (re)construção dos domínios conceptuais segundo os quais o processamento resulta de operações mentais que se indiciam nas representações verbais e, portanto, são ativados por expressões linguísticas.

Lakoff e Johnson (1980) centraram seus estudos na busca da compreensão dessa natureza mais abstrata da linguagem quando afirmaram que o pensamento e a linguagem são, em grande medida, figurativos. Para fins de recorte de pesquisa, nos concentramos apenas na geração do sentido metafórico por meio dos mapeamentos e, consequentemente, das metáforas e suas respectivas expressões linguísticas metafóricas, apontando caminhos para a identificação dos mecanismos que levam à compreensão da metaforicidade. Muitos são os autores que contribuíram e ainda desenvolvem pesquisas com o objetivo de aproximar linguagem, pensamento e processamento cognitivo. Entre eles, destacamos os trabalhos sobre metáfora de Lakoff e Johnson (1980), que se debruçaram sobre as implicações de uma metaforicidade que eles caracterizam como "corporificada". Os ${ }^{1}$ autores defendem que

\footnotetext{
${ }^{1}$ A Linguística Cognitiva postula que é impossível dissociar o mundo do significado do mundo da experiência, ou seja, conceber a linguagem à margem de todos os outros sistemas cognitivos. Assim, a Linguística Cognitiva rejeita que a linguagem seja um sistema autónomo ou uma faculdade humana autónoma em relação aos processos mentais, ao contrário das teorias linguísticas anteriores. Assume que a linguagem decorre das diferentes vertentes da experiência do homem no mundo, ou seja, das experiências corporais, físicas, apreendidas pelos sentidos, fruto do movimento relativo do corpo no espaço (daí a ênfase dos cognitivistas no carácter corpóreo da língua) em que se incluem também as experiências de interação social.
} 
o pensamento e a linguagem não são fenômenos "descorporificados", nem é a metáfora um caso especial de atividade verbal, unicamente característica da arte poética. Ao contrário, a metáfora é fundamental para o pensamento e muitos outros processos da cognição. Nesse sentido, a mente ganha relevância, ocorrendo uma mudança da base cognitiva e descorporificada para uma base cognitiva experiencial, com a mente corporificada. Nosso estudo leva em conta: (a) a linguagem como produto de uma experiência corporificada, ou seja, o corpo e a experiência herdada e construída determinam a estrutura conceptual; (b) a estrutura sintática e semântica derivam da e refletem a estrutura conceptual; e (c) a linguagem é dependente das restantes capacidades cognitivas, como a percepção, a memória e atenção. Leva-se em conta ainda o poder criativo / imaginativo da mente humana.

Nosso interesse na pesquisa consiste em tentar responder ao seguinte questionamento: quais são os mecanismos de mapeamento envolvidos na geração do sentido metafórico? Portanto, tivemos como objetivo principal descrever a estrutura da rede de mapeamentos conceptuais dos mecanismos responsáveis pela geração do sentido metafórico, motivo pelo qual escolhemos a Teoria da Metáfora Conceptual de Lakoff e Johnson (1980).

Nosso interesse pelo texto de jornal envolvendo o jogador Hulk (que tem o mesmo nome do personagem dos quadrinhos da Marvel) se justifica em função do número de metáforas associadas a esse personagem, o que permite uma análise da utilização das metáforas conceptuais. Portanto, tomamos como ponto de partida para as nossas inferências a notícia apresentada pelo jornal $O$ Povo, de 6 de junho de 2014. Por necessidade de personificar o jogador, certas comparações são feitas.

\section{A metáfora}

A partir da publicação, em 1980, do livro Metaphors we live by, de George Lakoff e Mark Johnson, ocorre uma ruptura com a visão que tinha a metáfora como apenas um ornamento poético, uma ilustração. A Teoria da Metáfora Conceptual assume que o sistema conceptual humano está alicerçado sobre um conjunto de conceitos oriundos da experiência, compreendidos via mapeamentos. Sendo assim, as expressões linguísticas metafóricas fazem sentido uma vez que elas são motivadas pelos mapeamentos conceptuais. Em outras palavras, elas são conceptualmente 
motivadas no sentido que há mecanismos cognitivos que desencadeiam a geração do significado metafórico. Entende-se que as metáforas estão presentes ativamente tanto na interpretação quanto na acessibilidade das expressões do cotidiano. As metáforas ajudam a compreender o mundo que nos cerca e, consequentemente, as novas formas de conceptualizar esse mundo.

Não é possível ignorar que falar de uma expressão conceptualmente motivada envolve aspectos ligados à sua figuratividade e literalidade. Além da metaforicidade que assumimos estar presente na geração do significado, há questões voltadas para sua interpretação que podem ser direcionadas tanto para o literal quanto para o figurado. Dependendo de uma ou outra interpretação se dará um ou outro sentido. Se a escolha for mais literal, a metaforicidade fica à margem da interpretação; enquanto que, se figurativa, a metaforicidade é amplamente utilizada para seu entendimento. Desse modo, "digerir uma ideia", por exemplo, parte de outras expressões em que ideias são faladas em termos de comida (LAKOFF; JOHNSON, 1980, p. 46).

Para que o leitor dê sentido ao que ouve, lê, escreve, a metáfora é auxiliada pelos domínios compreensíveis da experiência. Os conceitos são, assim, mapeados entre domínios (de domínios fontes para domínios alvo). Há quem afirme que o sentido literal é observado primeiro para só depois o indivíduo chegar ao sentido metafórico, ou seja, o indivíduo interpreta o significado metafórico somente depois de ter tentado, sem sucesso, encontrar um sentido literal. Isso levaria a um desgaste cognitivo, pois o individuo despenderia um maior esforço na busca do sentido apropriado. Esse é o motivo pelo qual afirmo que o sentido pode ser literal se assim o contexto indicar como, por exemplo, "pisar na jaca”. É possível que o indivíduo pise, de fato, na fruta denominada de jaca, mas se estivermos falando de um deslize de alguém, ou o fato de se cometer exageros, estaríamos no terreno da metáfora e, portanto, a composicionalidade da expressão idiomática indica a necessidade de uma interpretação metafórica. Com a ajuda do contexto, identificamos, imediatamente, o sentido metafórico e não passamos por uma leitura literal no processo de compreensão.

Em cada expressão metafórica, há pelo menos um, mas, frequentemente, mais de um traço em que o domínio fonte é mapeado em um traço correspondente no domínio alvo. Isso posto, podemos afirmar que o que constitui uma metáfora é parcialmente afetado pelo meio no qual 
ela ocorre - uma questão sócio-histórico-cultural. Nas palavras de Geeraerts (2006, p. 3), a língua envolve sempre o significado (language is all about meaning), pelo que a linguagem constitui um instrumento para organizar, processar e veicular informação. Com base nisso, pode-se afirmar que o significado faz uma articulação com a experiência física (concreta), e, com certeza, com a nossa experiência sócio-histórico-cultural.

Segundo Geeraerts (2006, p. 5, tradução nossa),

(...) nós também temos uma identidade cultural e social, e nossa língua pode revelar essa identidade, ou seja, as linguagens podem revelar essa identidade, ou seja, as linguagens / línguas podem corporificar a experiência histórica e cultural de grupos de falantes (e indivíduos). ${ }^{2}$

Para Gibbs (1999, p. 4, tradução nossa), "muitos aspectos de como nós entendemos a língua falada, interpretamos textos escritos e produzimos sentido de obras de arte são de certa forma influenciados pela procura por intenções comunicativas."’3

Outro aspecto a ser discutido quando da análise de metáforas é acerca da distinção entre mapeamentos metafóricos e metáfora. Temos de estabelecer uma desambiguação do próprio termo 'metáfora', por um lado; e evidenciar a sua natureza conceptual, por outro. Em outras palavras, o termo "metáfora" utiliza-se para designar os mapeamentos conceptuais entre domínios, enquanto o termo "expressão metafórica" se emprega para designar uma representação linguística individualizada destes últimos. Dessa forma, as expressões metafóricas constituem realizações linguísticas subjacentes das metáforas conceptuais.

Para facilitar a memorização dos diversos mapeamentos existentes no nosso sistema conceptual, Lakoff e Johnson (1980) adotaram uma estratégia de nomear cada mapeamento, utilizando mnemónicos, escritos com maiúsculas pequenas, por exemplo, LOVE IS A JOURNEY (O AMOR É UMA VIAGEM).

\footnotetext{
${ }^{2}(\ldots)$ we also have a cultural and social identity, and our language may reveal that identity, i.e. languages may reveal that identity, i.e. languages may embody the historical and cultural experience of groups of speakers (and individuals).

${ }^{3}$ Many aspects of how we understand spoken language, interpret written texts, and make sense of artworks, is to a significant extent influenced by the search for communicative intentions.
} 
Nós adotamos esta terminologia pela seguinte razão: Metáfora, como um fenômeno, envolve tanto mapeamentos conceptuais quanto expressões linguísticas individuais. É importante manter os termos distintos. Uma vez que os mapeamentos é que são primários e que isso se refere às generalizações que são nosso principal interesse, temos reservado o termo "metáfora" para os mapeamentos, mais do que para as expressões linguísticas. (...) Na literatura sobre esse campo, letras maiúsculas menores como o AMOR É UMA VIAGEM são usados como mnemônicos para nomear os mapeamentos. Assim, quando nos referimos à metáfora O AMOR É UMA VIAGEM, estamos nos referindo ao conjunto de correspondências discutidas acima. A sentença o amor é uma viagem, por outro lado, é uma expressão metafórica que é entendida via aquele conjunto de correspondências (LAKOFF apud GEERAERTS, 2006, p. 192-193, tradução nossa. $)^{4}$

É relevante ressaltar que é justamente essa diferenciação entre metáfora e expressões metafóricas, ou seja, o fato de uma metáfora conceptual poder tomar diversas formas por meio de expressões linguísticas metafóricas, que torna a metáfora um fenômeno conceptual. $\mathrm{Se}$, por outro lado, as metáforas fossem apenas expressões linguísticas, haveria possibilidade de ocorrer diferentes metáforas para diferentes expressões linguísticas.

No entanto, segundo Lakoff (2006), é fácil de comprovar que isso não acontece.

\footnotetext{
${ }^{4}$ We have adopted this terminology for the following reason: Metaphor, as a phenomenon, involves both conceptual mappings and individual linguistic expressions. It is important to keep them distinct. Since it is the mappings that are primary and that state the generalizations that are our principal concern, we have reserved the term "metaphor" for the mappings, rather than for the linguistic expressions. (...) In the literature of the field, small capitals like LOVE IS A JOURNEY are used as mnemonics to name mappings. Thus, when we refer to the LOVE IS A JOURNEY metaphor, we are referring to the set of the correspondences discussed above. The English sentence love is a journey, on the other hand, is a metaphorical expression that is understood via that set of correspondences. (LAKOFF apud GEERAERTS, 2006, p. 192-193).
} 
Se as metáforas fossem apenas expressões linguísticas, nós poderíamos esperar que diferentes expressões linguísticas fossem metáforas diferentes. Assim, Chegamos ao final da estrada constituiria uma metáfora. Não podemos voltar atrás agora uma outra, inteiramente diferente da anterior. Seu casamento está esfriando ainda uma metáfora diferente. E assim por diante, dezenas de exemplos. Parece-nos que não há dezenas de metáforas aqui. Temos apenas uma metáfora, na qual o amor é conceptualizado como uma viagem. Os mapeamentos nos dizem precisamente como o amor está sendo conceptualizado como uma viagem. E essa forma unificada de conceptualizar o amor metaforicamente é realizada em muitas diferentes expressões linguísticas (LAKOFF apud GEERAERTS, 2006, p. 192-193, tradução nossa). ${ }^{5}$

Podemos encontrar expressões linguísticas metafóricas em textos de diferentes áreas (esportivo, literatura, revistas em quadrinhos e assim por diante). Entre eles podemos citar a Bíblia, na qual o apóstolo São Paulo, em I Coríntios 9:24, usa os esportes em relação à vida cristã. Cristãos são comparados a corredores que pretendem alcançar o prêmio máximo: "Não sabeis vós que os que correm no estádio, todos, na verdade, correm, mas um só leva o prêmio? Correi de tal maneira que o alcanceis".

\section{Mapeamentos metafóricos}

O seriado "Hulk" é focado exclusivamente na figura do Dr. David Banner e seu alter ego. Em "Hulk", o motivo central que movimenta a narrativa e a ação do personagem é a busca do Dr. Banner da cura e o

\footnotetext{
${ }^{5}$ If metaphors were linguistic expressions, we would expect different linguistic expressions to be different metaphors. Thus, We've hit a dead-end street would constitute one metaphor. We can't turn back now would constitute another, entirely different metaphor. Their marriage is on the rocks would have still a different metaphor. And so on for dozens of examples. Yet we don't seem to have dozens of different metaphors here. We have one metaphor, in which love is conceptualized as a journey. The mapping tells us precisely how love is being conceptualized as a journey. And this unified way of conceptualizing love metaphorically is realized in many different linguistic expressions (LAKOFF apud GEERAERTS, 2006, p. 192-193).
} 
dilema entre o seu lado homem / monstro. Sendo assim, como se dariam esses mapeamentos metafóricos no caso de um jogador de futebol ter como codinome o mesmo do personagem Hulk? Inicialmente é interessante delinearmos nosso entendimento do que seja mapeamento metafórico. Para tanto, nos valemos do que é dito por Kövecses (2006, p. 118-125). Inicialmente o autor afirma (p. 118) que na visão tradicional da metáfora a similaridade é a motivação principal para juntar dois conceitos em uma relação metafórica, mas ele dá igual importância para as correlações na experiência do corpo. Kövecses (Op. cit., p. 119) afirma que certos gatilhos acionam uma analogia em particular, compartilhando elementos dos domínios fonte e alvo. Ou seja, um determinado traço que é compartilhado por um elemento do alvo e um elemento da fonte ajuda o leitor a chegar a um extensivo conjunto de relações analógicas entre a fonte e o alvo da metáfora. Para o autor, em muitos casos, o elemento compartilhado não é um traço tão óbvio. Em geral, o alvo e a fonte são caracterizados por relações estruturais similares - sem nenhum traço compartilhado da situação comunicativa que deve engatilhar a recognição das relações compartilhadas. O que é reconhecido entre os dois domínios não precisa ser algo tão abstrato quanto à estrutura de nível genérico. Pode haver similaridades de todos os tipos - reais ou percebidas.

A partir dessas colocações, Kövecses (2006, p. 119-120) passa a se posicionar quanto às conexões na mente humana. Ele afirma que é o cérebro que faz funcionar o corpo, e se a metáfora está no corpo, então, ela deve também estar no cérebro. As experiências corporificadas, por esse ponto de vista, resultam em certas conexões neurais entre áreas do cérebro (estas áreas correspondem aos domínios fonte e alvo). Ele dá como exemplo o fato de quando a área do cérebro que corresponde a afeição é ativada, a área que corresponde ao calor também é ativada. Pensa-se que quando o indivíduo entende conceitos abstratos metaforicamente, dois grupos de neurônios no cérebro são ativados ao mesmo tempo; quando um grupo de neurônios que corresponde ao domínio fonte é ativado, outro grupo de neurônios do domínio alvo também é.

Resumindo, Kövecses (2006, p. 120, tradução nossa) afirma que

as metáforas conceptuais são conjuntos de neurônios em diferentes partes do cérebro conectados pelo circuito neuronal. Os conjuntos de neurônios localizados em diferentes partes do cérebro são os domínios fonte e alvo, e os circuitos neurais físicos que os conectam são os 
mapeamentos. Isso permite que a metáfora seja vista como física (neuronal) e estruturas do cérebro. Para dar sentido a metáfora é necessário que conexões apropriadas neuronais sejam "recrutadas" entre diferentes partes do cérebro. ${ }^{6}$

Para Kövecses (2006, p. 122), há correspondências conceptuais essenciais e básicas, denominadas de mapeamentos entre os domínios fonte e alvo. Ele dá como exemplo (QUADRO 1) o conjunto de mapeamentos para a metáfora O AMOR É UMA VIAGEM (LOVE IS A JOURNEY):

Quadro 1 - Mapeamentos para a metáfora O AMOR É UMA VIAGEM.

\begin{tabular}{lll}
\hline Fonte: VIAGEM & & Alvo: AMOR \\
\hline Viajantes & $\longrightarrow$ & amantes \\
Veículo & relacionamento amoroso \\
Destino & $\longrightarrow$ propósito para a relação \\
Distância coberta & $\longrightarrow$ progresso feito na relação \\
Obstáculos ao longo do caminho $\longrightarrow$ & $\begin{array}{l}\text { dificuldades encontradas na } \\
\text { relação }\end{array}$ \\
\hline
\end{tabular}

Fonte: Kövecses (2006, p. 122).

Os mapeamentos devem ser colocados de tal forma que expliquem expressões linguísticas metafóricas em particular. Portanto, uma metáfora conceptual é um conjunto de correspondências que ocorrem entre os domínios fonte e alvo, que se manifestam em expressões linguísticas metafóricas, de tal maneira que a metáfora possa ser expressa. Sendo assim, o conhecimento do indivíduo a respeito dos conceitos são necessários para se entender os relacionamentos entre os domínios.

${ }^{6}$ Conceptual metaphors are ensembles of neurons in different parts of the brain connected by neuronal circuitry. The ensembles of neurons located in different parts of the brain are the source and target domains, and the physical neural circuitry that connects them is the mappings. This allows us to see metaphor as physical (i.e., neural) structures of the brain. 
Para Kövecses (2006, p. 123), os domínios fonte frequentemente mapeiam ideias no alvo, além das correspondências básicas. Esses mapeamentos adicionais são denominados de inferências ou acarretamentos (entailments). Se AMOR é conceptualizado como VIAGEM e o veículo corresponde ao relacionamento, então o conhecimento sobre o veículo pode ser usado para entender os relacionamentos amorosos. Portanto, o autor conclui que, quando se sugere que uma metáfora conceptual pode ser vista com uma estrutura como A é B, isso não significa que o conceito por inteiro A ou B esteja envolvido - apenas aspectos seletivos deles. Sendo assim, nem todos os conceitos do domínio fonte são projetados no domínio alvo. Porém, podem, eventualmente, duas contrapartes serem projetadas e amalgamadas no alvo e, outras vezes, apenas uma. Se houver falta de compreensão por parte do indivíduo, é provável que nenhum conceito tenha sido projetado e, portanto, ou não se tem significação, ou um sentido literal, não metafórico. Trata-se de um trabalho inconsciente na construção do significado. Os estudiosos buscam identificar, em geral, como se compõe esse significado e como se dão essas projeções.

Conforme se dão as projeções e são realizados os mapeamentos, podemos estar diante de uma rede ampla de sentidos, recrutando novas estruturas para o domínio alvo, tornando-as disponíveis para possíveis projeções.

Sendo assim, como seria possível estabelecer alguns mapeamentos metafóricos entre o personagem Hulk e o jogador de futebol Hulk? Tentamos abaixo evidenciar alguns possíveis aspectos envolvidos nesse processo (QUADRO 2):

Quadro 2 - Possíveis mapeamentos metafóricos Hulk - personagem de filmes e quadrinhos e jogador de futebol

\begin{tabular}{lll}
\hline $\begin{array}{c}\text { Fonte: HULK } \\
\text { (personagem) }\end{array}$ & Mapeamentos & \multicolumn{1}{c}{$\begin{array}{c}\text { Alvo: HULK } \\
\text { (jogador) }\end{array}$} \\
\hline CIENTISTA & $\longrightarrow$ & JOGADOR \\
FORÇA & $\longrightarrow$ & FORÇA \\
VENERADO POR CRIANÇAS & $\longrightarrow$ & VENERADO POR TORCEDORES \\
VELOZ & $\longrightarrow$ & VELOZ \\
DESTRUIDOR & $\longrightarrow$ & GOLEADOR \\
VERDE DO CORPO & & VERDE DO CORPO \\
RESISTÊNCIA AOS ATAQUES DOS & $\longrightarrow$ & RESISTÊNCIA AOADVERSÁRIO \\
INIMIGOS & $\longrightarrow$ & \\
\hline
\end{tabular}

Fonte: autor do texto. 
570 Revista de Estudos da Linguagem, Belo Horizonte, v. 23, n.2, p. 559-580, 2015

\section{O texto}

A escolha do texto para a análise teve por objetivo observar as variedades de possibilidades metafóricas em um texto jornalístico referente ao esporte futebol e, mais especificamente, ao jogador da seleção brasileira chamado de Hulk. O texto está repleto de metáforas, o que exige do leitor poder criativo, imaginativo. Retiramos os dados do jornal O Povo, de 06/06/2014, p. 3 . O autor do texto é Aflaudísio Dantas.

No texto (FIGURA 1) vemos que o jogador é representado pictoricamente e metaforicamente como um herói Marvel. Há, portanto, duas modalidades envolvidas no artigo, motivo pelo qual podemos denomina-lo de verbo-pictórico. Há um grande interesse em discutirmos a imagem e seu potencial na geração do sentido, mas, no momento, voltaremos nossa atenção apenas para a linguagem verbal do texto e sua metaforicidade.

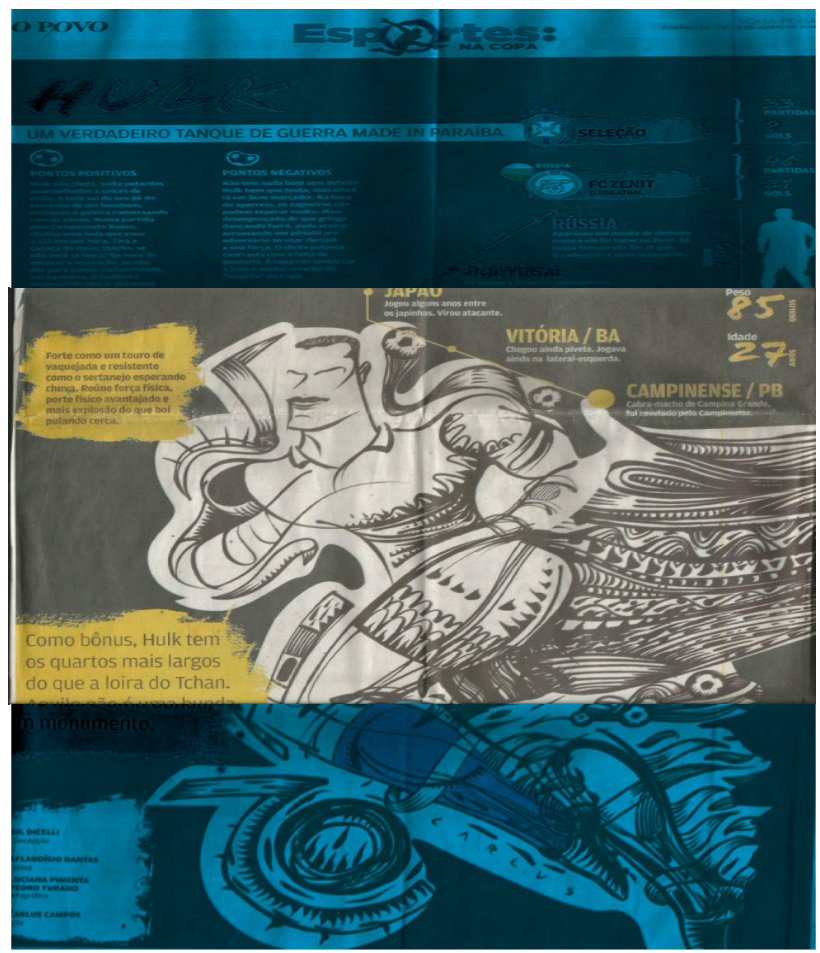

Fonte: Jornal O Povo, de 06/06/2014, p. 3.

Figura 1 - Texto do jornal O Povo sobre o jogador de futebol Hulk. 
Não podemos ignorar que a imagem, nesse caso, tem uma implicação na interpretação do texto, mas, no momento, nos dedicaremos apenas à linguagem verbal do texto. Sendo assim, passamos a transcrever o texto verbal para facilitar sua leitura e análise.

Transcrição do texto da Figura 1:

Hulk; um verdadeiro tanque de guerra made in Paraíba

Pontos positivos

Hulk não chuta, solta petardos assemelhados a coices de mula. A bola sai do seu pé do tamanho de um bombom, deixando o goleiro conversando com as almas. Numa partida pelo Campeonato Russo, chutou uma bola que voou a $125 \mathrm{~km}$ por hora. Tira a cabeça do meio, macho, se não você se lasca! Na hora de encarar a marcação, se não der para passar na habilidade, vai na marra. $\mathrm{O}$ homem é desassombrado! Ir pro mano a mano com o Hulk é pedir pra dar uma passada no IJF.

Pontos Negativos

Não tem nada de bom sem defeito. Hulk bem que tenta, mas não é lá um bom marcador. Na hora do aperreio, os zagueiros não podem esperar muito. Mais desengonçado do que gringo dançando forró, pode acabar arrumando um pênalti pro adversário ou usar demais a sua força. O chute potente contrasta com a falta de pontaria. É capaz de (4) embarcar a bola e acabar o racha da "negada" da Copa.

Forte como um touro de vaquejada e resistente como o sertanejo esperando chuva. Reúne força física, porte físico avantajado e mais explosão do que boi pulando cerca.

Como bônus, Hulk tem os quartos mais largos do que a loira do Tchan. Aquilo não é uma bunda, é um monumento.

Com base nesse texto, podemos considerar as seguintes metáforas (M) e respectivas expressões metafóricas (EM):

(1) M - JOGADOR É UMA ARMA BÉLICA

EM -"Hulk; um verdadeiro tanque de guerra made in Paraíba" 
(2) M - JOGADOR É UM ANIMAL

EM - "Hulk não chuta, solta petardos assemelhados a coices de mula" EM - "Forte como um touro de vaquejada"

EM - "Reúne força física, porte físico avantajado e mais explosão do que boi pulando cerca"

(3) M - JOGADOR É UM DANÇARINO

EM - "Mais desengonçado do que gringo dançando forró"

EM - "Como bônus, Hulk tem os quartos mais largos do que a loira do Tchan"

(4) M - JOGADOR É UM EMBARCADOR DE BOLA

EM - "É capaz de (4) embarcar a bola e acabar o racha da "negada" da Copa"

(5) M - JOGADOR É UM SERTANEJO RESISTENTE

EM - "Resistente como o sertanejo esperando chuva"

(6) M - JOGADOR É UM MONUMENTO

EM - "Aquilo não é uma bunda, é um monumento"

(7) M - JOGADOR É UM LUTADOR

EM - "Na hora de encarar a marcação, se não der para passar na habilidade, vai na marra"

EM - "Ir pro mano a mano com o Hulk é pedir pra dar uma passada no IJF"

(8) M - A BOLA É UM DARDO CERTEIRO

EM - "Numa partida pelo Campeonato Russo, chutou uma bola que voou a $125 \mathrm{~km}$ por hora"

EM - "O chute potente contrasta com a falta de pontaria"

(9) M - A BOLA É UMA BALA/PROJÉTIL/ARMA

EM - "A bola sai do seu pé do tamanho de um bombom? deixando o goleiro conversando com as almas"

\footnotetext{
${ }^{7}$ Essa expressão linguística regional "do tamanho de um bombom" é também muito usada nas periferias de Fortaleza. Tem como significado a alta velocidade com que algo se desloca, pois quando tentamos visualizá-la, é difícil definir suas formas, daí se dizer, por exemplo, que "Fulano passou por aqui do tamanho de um bombom". Nesse caso, então, a metáfora seria a de que a bola é pura velocidade, ou algo nesse sentido.
} 
Mapeamentos diversos dão origem a diferentes realizações metafóricas, por exemplo: JOGADOR É UM ANIMAL que dá origem a: Hulk não chuta, solta petardos assemelhados a coices de mula e Forte como um touro de vaquejada. Soltar petardos poderia também ser incluso na metáfora: JOGADOR É UMA ARMA BÉLICA, pois petardo se refere a bomba. Portanto, as metáforas e seus mapeamentos envolvem um objetivo final do jogador, que é marcar o gol. Para isso, o autor se vale de expressões que metaforizam o jogador em diferentes aspectos. Vejamos como, possivelmente, se constituem algumas das metáforas e suas correspondentes expressões linguísticas metafóricas:

(1) JOGADOR É UMA ARMA BÉLICA - dá origem a realizações metafóricas cujo domínio fonte incide sobre o domínio alvo, levando em conta as projeções relativas aos atributos de armas de guerra, no caso, tanque de guerra próprio desse cenário. As propriedades que são atribuídas ao tanque de guerra: FORTE, RESISTENTE, QUASE INDESTRUTÍVEL, são projetadas seletivamente no jogador. Dessa maneira, vemos o jogador por outro ponto de vista. Uma abstração do potencial do tanque de guerra transferido para o jogador, em vez de simplesmente dizer que o jogador é forte.

(2) JOGADOR É UM ANIMAL - leva a realizações metafóricas cujo domínio-fonte incide sobre o domínio-alvo, levando em conta as projeções relativas aos atributos de animais, no caso, coices de mula e forte como um touro, próprios desse cenário. Nesse caso, a escolha do animal define o tipo de característica que se deseja transferir para o jogador. Na escolha da mula, temos a persistência, a potência do coice que, quando colocada na bola, indica a força do chute do jogador. Já quando se quis atribuir força ao jogador, o touro é usado como metáfora (comparação). $\mathrm{O}$ animal no domínio fonte da metáfora facilita a criação de imagens mentais que propiciam uma melhor avaliação do domínio alvo.

(3) JOGADOR É UM DANÇARINO - é concretizada em imagens metafóricas construídas em torno do domínio fonte das danças, no caso, o forró dançado por um gringo, ou seja, que se supõe desengonçado, fora do ritmo. Das danças, poderia ter sido escolhido qualquer ritmo e, dependendo dessa escolha, definiria quem é esse dançarino. $O$ fato de ser um "gringo" também influencia na composição do sentido. 
(4) JOGADOR É UM EMBARCADOR DE BOLA ${ }^{8}-\mathrm{a}$ conceptualização exige um maior esforço cognitivo, pois é concretizada pela imagem de um embarcador de malas metaforizado por um embarcador de bolas. Um embarcador de malas tem um destino para enviá-las. O jogador também tem um destino para a bola. Aqui há uma conceptualização entre MALA e BOLA, EMBARCADOR e JOGADOR.

(5) JOGADOR É UM SERTANEJO RESISTENTE - realiza-se em imagens metafóricas que tomam como domínio fonte a problemática do sertanejo que espera chuva para que a terra produza. Sua agricultura e sobrevivência dependem das águas das chuvas. O jogador, ao ser conceptualmente metaforizado como um sertanejo "resistente", indica que ele é persistente e não desiste de seus objetivos. No caso do sertanejo, temos a plantação e a esperança pela chuva; para o jogador, sua insistência é pelo gol que define o vencedor da partida.

JOGADOR É UM MONUMENTO - dá origem a imagens metafóricas que apresentam como domínio fonte uma parte do corpo do jogador que é comparada a um monumento, ou seja, uma obra de arquitetura ou escultura destinada a perpetuar para a posteridade a lembrança de um grande personagem ou acontecimento. Nesse caso, não são as qualidades como jogador de futebol que estão em jogo, mas uma parte do corpo em particular que se destaca. Quando o autor do texto diz que "aquilo não é uma bunda, é um monumento", ele está analisando o jogador por outros aspectos que não sua habilidade com a bola.

JOGADOR É UM LUTADOR - Dá origem a realizações metafóricas cujo domínio fonte incide sobre adversários, táticas e meios técnicos próprios dos cenários de luta. Nesse cenário, imagina-se que o lutador pretende derrubar o adversário, maneira que demonstra que é um vencedor. No caso da expressão "Ir pro mano a mano com o Hulk é pedir pra dar uma passada no IJF", indica que, se o adversário se colocar

\footnotetext{
${ }^{8}$ A expressão "embarcar a bola" é utilizada nas periferias de Fortaleza quando pessoas estão jogando futebol. Embarcar a bola significa chutar a bola tão forte que ela chega a sair do campo de jogo (ou da rua), e a cair em quintais de casas ou outros locais privados. Percebe-se que o autor desse texto procurou empregar essa expressão linguística usada quando se joga futebol em Fortaleza, visto que muitos dos leitores da seção de esportes do jornal O Povo, já a utilizou ou ainda a usam, provocando uma identificação com o texto e reforçando as metáforas empregadas nele.
} 
na frente do jogador o impedindo de realizar seu intento de marcar o gol, ele será capaz de enfrentá-lo e a sua força poderá levar o adversário ao $\mathrm{IJF}^{9}$, ou seja, ao hospital.

Vale ressaltar que o autor do texto quis empregar expressões metafóricas utilizadas por pessoas da periferia de Fortaleza, principalmente quando estão jogando futebol. Uma interpretação aproximada do leitor sobre o que o autor pretendeu comunicar depende, logicamente, da experienciação sócio-histórica de quem lê o artigo. As metáforas contextualmente não se tornam difíceis de serem interpretadas. No caso

A BOLA É UM DARDO CERTEIRO - a concretização se dá por meio de um domínio fonte visto como um dardo que tem como alvo um único destino - no caso do jogo e da bola, é o gol. Nesse caso, há um elogio e uma crítica ao jogador. Quando afirma que "Numa partida pelo Campeonato Russo, chutou uma bola que voou a $125 \mathrm{~km}$ por hora", o texto ressalta a força do chute do jogador, o que é um ponto positivo, mas, quando afirma que "O chute potente contrasta com a falta de pontaria", é uma observação negativa. O jogador acerta a bola com muita força, mas não acerta o ALVO, o gol.

A BOLA É UMA BALA / ARMA / (UM) PROJÉTIL - origina a construção de imagens metafóricas cujo domínio fonte é relativo a um doce, no caso, um bombom (que no Ceará é o mesmo que a bala de São Paulo); elementos gerais ligados à esse doce: pequeno, por exemplo. Ao afirmar que "A bola sai do seu pé do tamanho de um bombom", o autor quis reforçar a agilidade do jogador no trato com a bola e destacar a velocidade com que a ela sai dos seus pés, resultante de sua força. Portanto, por ser pequeno, pode ser comparada a um doce, ou a um projétil de arma de fogo. Em função da expressão "conversando com as almas", que pode significar algo como conversando com algo invisível ou com "mortos", podemos entender a metáfora como se referindo a algo que passa imperceptível. A expressão chama atenção para a bola, mas é o jogador que a domina.

${ }^{9}$ IJF - Instituto Dr. José Frota - é o hospital de Fortaleza mais conhecido para tratar urgências traumatológicas. Aqui também se utilizou da figura do IJF para reforçar uma metáfora e atrair o leitor-alvo. 
desse estudo, vimos que são usadas diferentes metáforas para caracterizar o jogador de futebol. As metáforas aqui apresentadas fazem uso da fórmula A é B, que é típica das metáforas, mas as expressões linguísticas metafóricas não seguem necessariamente essa fórmula. Uma primeira constatação é de que essas expressões são claramente não literais: um jogador não solta petardos, ou é uma mula ou um touro.

Disso decorre o fato de que a linguagem metafórica está relacionada a um sistema metafórico subjacente, um "sistema do pensamento". De certa forma, é possível notar que não se pode escolher qualquer domínio conceptual aleatoriamente com a finalidade de descrever um jogador como uma mula, por exemplo. Isso leva à hipótese de que há um elo convencional no nível conceptual entre o domínio ANIMAL e o domínio JOGADOR. Segundo esse ponto de vista, o JOGADOR, que é o domínio alvo (o domínio a ser descrito), é convencionalmente estruturado em termos de ANIMAL, que é o domínio fonte (o domínio em termos do qual o alvo é descrito). Pelas leituras em revistas em quadrinhos, nas histórias do Hulk, há nele uma metáfora que envolve domínio fonte ANIMAL para um domínio alvo - o Dr. Bruce Banner, um CIENTISTA. O personagem Hulk é um homem fortíssimo e animalizado, que raciocina muito pouco e é altamente destrutivo. Sendo assim, é possível que o autor da matéria jornalística tenha feito uma ligação entre um animal (mula e touro persistente, resistente e forte) e a personalidade e força do jogador. Essa associação convencional de um domínio com outro é que caracteriza a metáfora. O que a torna conceptual (mais que puramente linguística) é a ideia de que a motivação para a metáfora reside no nível de domínios conceptuais. Isso é o que levou Lakoff e Johnson (1980) à conclusão de que não apenas falamos em termos metafóricos mas também pensamos em termos metafóricos. Dessa perspectiva, as expressões linguísticas que são por natureza metafóricas são simplesmente reflexos de uma associação conceptual subjacente (EVANS; GREEN, 2007, p. 295).

Há um certo número de papéis distintos que estão envolvidos nos domínios fonte e alvo. Por exemplo, na metáfora JOGADOR É UM ANIMAL, o domínio alvo JOGADOR inclui BOLA, CAMPO DE FUTEBOL, JUIZ, REGRAS, UNIFORME, TÉCNICO, ADVERSÁRIO, enquanto o domínio fonte envolve FORÇA, BRAVEZA, ASTÚcia, etc. A metáfora trabalha mapeando os papéis da fonte no alvo. Isso implica que um elo metafórico entre dois domínios consiste de um número de correspondências distintas ou mapeamentos (QUADRO 3). 
Quadro 3 - Mapeamentos metafóricos

\begin{tabular}{lll}
\hline Fonte: ANIMAL & Mapeamentos & Alvo: JOGADOR \\
\hline JOGADOR & $\longrightarrow$ & ANIMAL \\
FORÇA & $\longrightarrow$ & FORÇA \\
PREDADORES & $\longrightarrow$ & ADVERSÁRIOS \\
DECISÃO DE QUANDO ATACAR & $\longrightarrow$ & DRIBLES / ATAQUE \\
PRESA CAPTURADA & $\longrightarrow$ & GOL \\
\hline
\end{tabular}

Fonte: autor do texto.

O que se pode afirmar com base nesses mapeamentos é que a metáfora conceptual JOGADOR É UM ANIMAL tem uma forte base experiencial. As correlações entre os domínios conceptuais tem uma íntima ligação com as experiências do cotidiano. Segundo Lakoff e Johnson (1980), esse tipo de correlação, experienciada no dia a dia, aumenta a possibilidade da formação de uma associação no nível conceptual, que é refletido nos exemplos linguísticos. Segundo essa visão, as metáforas conceptuais são sempre, pelo menos parcialmente, motivadas pela base experiencial. Isso potencializa os mapeamentos entre os domínios fonte e alvo.

Segundo Fauconnier (1997), há três tipos de operações de mapeamento: (1) as projeções de mapeamento - que projetam estruturas de um domínio (fonte) para outro (alvo), típicos da metáfora conceptual; no caso da metáfora JOGADOR É UM ANIMAL, o JOGADOR é conceptualizado em termos de ANIMAL; (2) mapeamentos com função pragmática - são estabelecidas entre duas entidades compartilhando os frames de experiência; e (3) esquemas de mapeamento - em que as operações estão relacionadas à projeção de esquemas (outro termo para frame) em uma expressão particular. É interessante lembrar que um frame é uma estrutura de conhecimento derivada do cotidiano das interações sociais.

Muito se diz que os mapeamentos são unidirecionais. Evans e Green (2007, p. 297) se perguntam se há um modelo em termos do qual os domínios conceptuais tipicamente funcionam como domínios fonte, e quais como domínio alvo. Outra questão envolve o que motiva tal modelo. Kövecses (2002) depois de muita pesquisa chegou à conclusão 
de que os domínios fonte mais comuns para mapeamentos incluem domínios relacionados ao CORPO HUMANO (O coração do problema), ANIMAIS (Ele é uma tartaruga), PLANTAS (Esse resultado é fruto de nosso esforço), ALIMENTO (Ele ficou cozinhando as ideias) e FORÇAS (Não me empurre). Os mais comuns domínios alvo incluem categorias conceptuais, tais como EMOÇÃO (Ele estava profundamente mudado), MORALIDADE (Resistir à tentação), RELACIONAMENTO HUMANO (Ele construiu um casamento forte) e TEMPO (O tempo voa).

Segundo Kövecses (2002, p. 20, tradução nossa), "os domínios são abstratos, difusos e falta uma definição clara; como resultado eles 'clamam' por uma conceptualização metafórica" "10. Embora firmados em experiências corporificadas mais básicas, esses conceitos se relacionam a estruturas de conhecimento experienciais mais complexas e abstratas.

\section{Considerações finais}

Como vimos, uma linha importante de investigação na Linguística Cognitiva tem seu foco sobre como a língua reflete a estrutura conceptual, ou seja, como se dão os mecanismos que estruturam a conceptualização. Os mapeamentos, nesse caso, oferecem uma estrutura conceptual, revelando os elementos do significado apresentados nas expressões linguísticas metafóricas.

Levando-se em conta que o pensamento é em grande parte metafórico, entendermos como se dá o processamento para geração do sentido nos capacita a entender as comunicações entre os indivíduos. As metáforas que regem as expressões metafóricas facilitam a categorização e, consequentemente, a recuperação de informações. Supõe-se que, por ser algo inconsciente, o processamento não seja percebido pelo indivíduo, isto é, não se reflete no momento da geração do sentido acerca de qual expressão metafórica está sendo regida por qual metáfora; no entanto, para pesquisadores, é importante saber como se dá esse processo.

No âmbito deste estudo, observamos a importância das metáforas conceptuais e respectivas realizações metafóricas na esfera da imprensa desportiva. Pode, assim, comprovar-se o postulado basilar da

\footnotetext{
${ }^{10}$ Target domains are abstract, diffuse and lack clear delineation; as a result they "cry out" for metaphorical conceptualization.
} 
semântica cognitiva de que o significado é indissociável da experiência física, social e cultural, pelo que experiências diferentes dão origem a metáforas conceptuais e imagens metafóricas diferentes. Dessa maneira, constatamos que a metáfora não apenas compõe a linguagem cotidiana mas demonstra uma visão de mundo conforme a sociedade em que está inserida.

Há muito o esporte está em consonância com a metáfora no diaa-dia dos indivíduos. Há uma busca da razão e da sensibilidade, um novo uso da linguagem esportiva. Por fim, isso estimula nossas consciências, nossa capacidade reflexiva e imaginativa quanto às suas possibilidades.

Por meio das metáforas, a mensagem é enviada de maneira direta, emotiva e criativa, facilitando a compreensão de um possível conceito que precisaria de muito esforço cognitivo para ser explicado. Os recursos metafóricos transportam para situações análogas a que estamos vivenciando em determinado momento.

\section{Referências}

DANTAS, Aflaudísio. Hulk; um verdadeiro tanque de guerra made in Paraíba. O Povo, Fortaleza, 06/06/2014, Esportes, p. 3.

EVANS, Vyvyan; GREEN, Melanie. Cognitive Linguistics An Introduction. Edinburgh: Edinburgh University Press, 2007.

FAUCONNIER, Gilles. Mappings in Thought and Language. Cambridge: Cambridge University Press, 1997.

GEERAERTS, Dirk. Introduction. A rough guide to Cognitive Linguistics. In: Cognitive Linguistics: Basic Readings. Ed. Dirk Geeraerts. Berlin: Mouton de Gruyter, 2006. p. 1-28.

GIBBS, R. W. Taking metaphor out of our heads and putting it in the cultural world. In: GIBBS, R. W.; STEEN, G. J. (Ed.). Metaphor in Cognitive Linguistics. Amsterdam: John Benjamins Publishing Co, , 1999. p. 145-167.

KÖVECSES, Zoltán. Metaphor - A Practical Introduction, Oxford: Oxford University Press, 2002.

Metaphor and emotion: language, culture, and body in human feeling. New York: Cambridge University Press, 2000.

Language, Mind and Culture: a practical introduction. Oxford: Oxford University Press. 2006. 
580 Revista de Estudos da Linguagem, Belo Horizonte, v. 23, n.2, p. 559-580, 2015

LAKOFF, George. Women, Fire and Dangerous Things: What Categories Reveal about the Mind, Chicago: Chicago University Press, 1987.

LAKOFF, George; JOHNSON, Mark. Metaphors We Live by. Chicago: Chicago University Press, 1980. 